\title{
Sequence Effects in Donor-Acceptor Oligomeric Semiconductors Comprising Benzothiadiazole and Phenylenevinylene Monomers
}

\author{
Shaopeng Zhang, ${ }^{\dagger}$ Nicole E. Bauer, ${ }^{\S}$ Ilana Y. Kanal, ${ }^{\dagger}$ Wei You, ${ }^{\S, \perp \odot ~ G e o f f r e y ~ R . ~ H u t c h i s o n, ~}{ }^{*},+, I_{\odot}$ \\ and Tara Y. Meyer*, ${ }^{\dagger}+$ (1) \\ ${ }^{\dagger}$ Department of Chemistry, University of Pittsburgh, Pittsburgh Pennsylvania 15260, United States \\ ${ }^{\S}$ Department of Chemistry, University of North Carolina at Chapel Hill, Chapel Hill, North Carolina 27599, United States \\ ${ }^{\perp}$ Department of Applied Physical Sciences, University of North Carolina at Chapel Hill, Chapel Hill, North Carolina 27599, United \\ States \\ "IDepartment of Chemical Engineering University of Pittsburgh, Pittsburgh, Pennsylvania 15260, United States \\ ${ }^{\ddagger}$ McGowan Institute for Regenerative Medicine, University of Pittsburgh, Pittsburgh, Pennsylvania 15219, United States
}

\begin{abstract}
To understand the influence of monomer sequence on the properties and performance of conjugated oligomers, a series of dimers, trimers, and tetramers were prepared from phenylene (P) and benzothiadiazole (B) monomers linked by vinylene groups. Optical and electrochemical studies established the influence of sequence on both the $\lambda_{\max }$ and redox potentials of this series of structurally related oligomers. For tetramers with bromo end groups (PBBP, BPPB, PBPB, PPBB), the $\lambda_{\max }$ ranged from 493 to $512 \mathrm{~nm}(\Delta$ $=19 \mathrm{~nm}$ ), the electrochemical oxidation potential from 0.65 to $0.82(\Delta=0.17 \mathrm{~V})$ and the reduction potential from -1.45 to

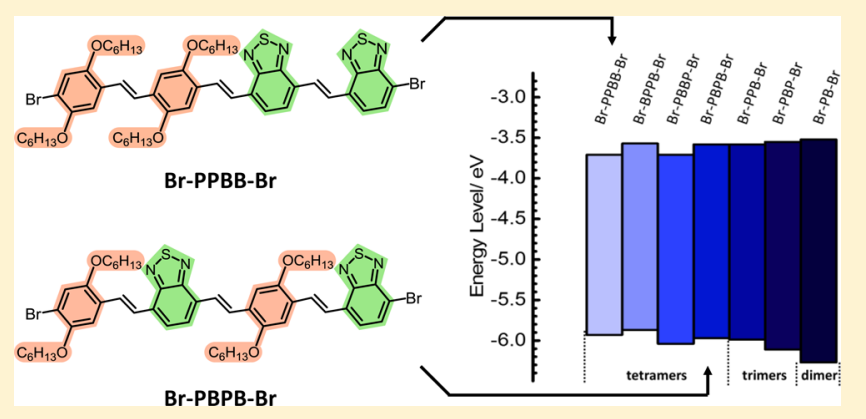
$-1.31(\Delta=0.14 \mathrm{~V})$, all of which are sequence-dependent. The effect of end groups (cyano, bromo, and alkyl) was also demonstrated to be important for the properties of these oligomers. DFT calculations of the tetramers were performed and the energy levels were correlated well with the experimentally determined spectroscopic data. Bulk heterojunction ( $\mathrm{BHJ}$ ) solar cells fabricated with selected tetramers as the donor and $\mathrm{PC}_{61} \mathrm{BM}$ as the acceptor exhibited power conversion efficiencies that varied by a factor of 3 as a function of sequence $(0.47-1.85 \%)$. These results suggest that sequence control is important for tuning optoelectronic properties and photovoltaic performance of these structurally related conjugated oligomers.
\end{abstract}

\section{INTRODUCTION}

The power and potential of conjugated organic materials stems from their rich diversity and ease of tailoring key properties including optical band gap, absorption and emission intensities, packing, and charge transport properties. $^{1-4}$ Applications include photovoltaics, efficient organic light-emitting displays, photocatalytic systems, polymer batteries and supercapacitors, and more. ${ }^{3,5-11}$ While the majority of the conjugated materials have been polymeric systems, more recent scientific efforts have demonstrated that oligomers, with complete control over chain length, chain ends, and chemical purity, offer unique advantages. $5,6,9,10,12$

Controlling monomer sequence is increasingly used to engineer properties in (nonconjugated) copolymers, but has not been widely exploited in conjugated systems. ${ }^{13-15}$ In order to achieve desirable properties for these applications-oriented conjugated polymers, researchers have largely focused on designing increasingly sophisticated repeat units, ${ }^{2,16}$ tailoring side-chains, ${ }^{17,18}$ and combining electron-rich and electron-poor monomers (donor-acceptor strategy). ${ }^{3,19-23}$ Some efforts have also focused on the use of end group modification to control $p$ - and $n$-type carrier transport, oxidation and reduction potentials, and optical properties. ${ }^{6,24}$ Nevertheless, sequence remains largely unexplored in these conjugated materials; in contrast, results from nonconjugated materials have demonstrated that sequence control is important and has significant impact on properties of materials. ${ }^{25-35}$

We are interested in applying the sequence control strategy to conjugated oligomers and polymers; more importantly, we intend to study these structurally related materials to understand the effects of sequence on properties related to the use of these materials in photovoltaic devices. Though scarcely reported, there have been some promising examples of sequence effects. ${ }^{26,36-39}$ For example, Liang and co-workers reported that two sequence-isomeric conjugated oligomers exhibited power conversion efficiencies that were significantly different, $4.53 \%$ vs $1.58 \% .^{39}$ Sequence-based differences in morphology were also observed by Palermo et al. in their

Received: October 11, 2016

Revised: December 7, 2016

Published: December 22, 2016 

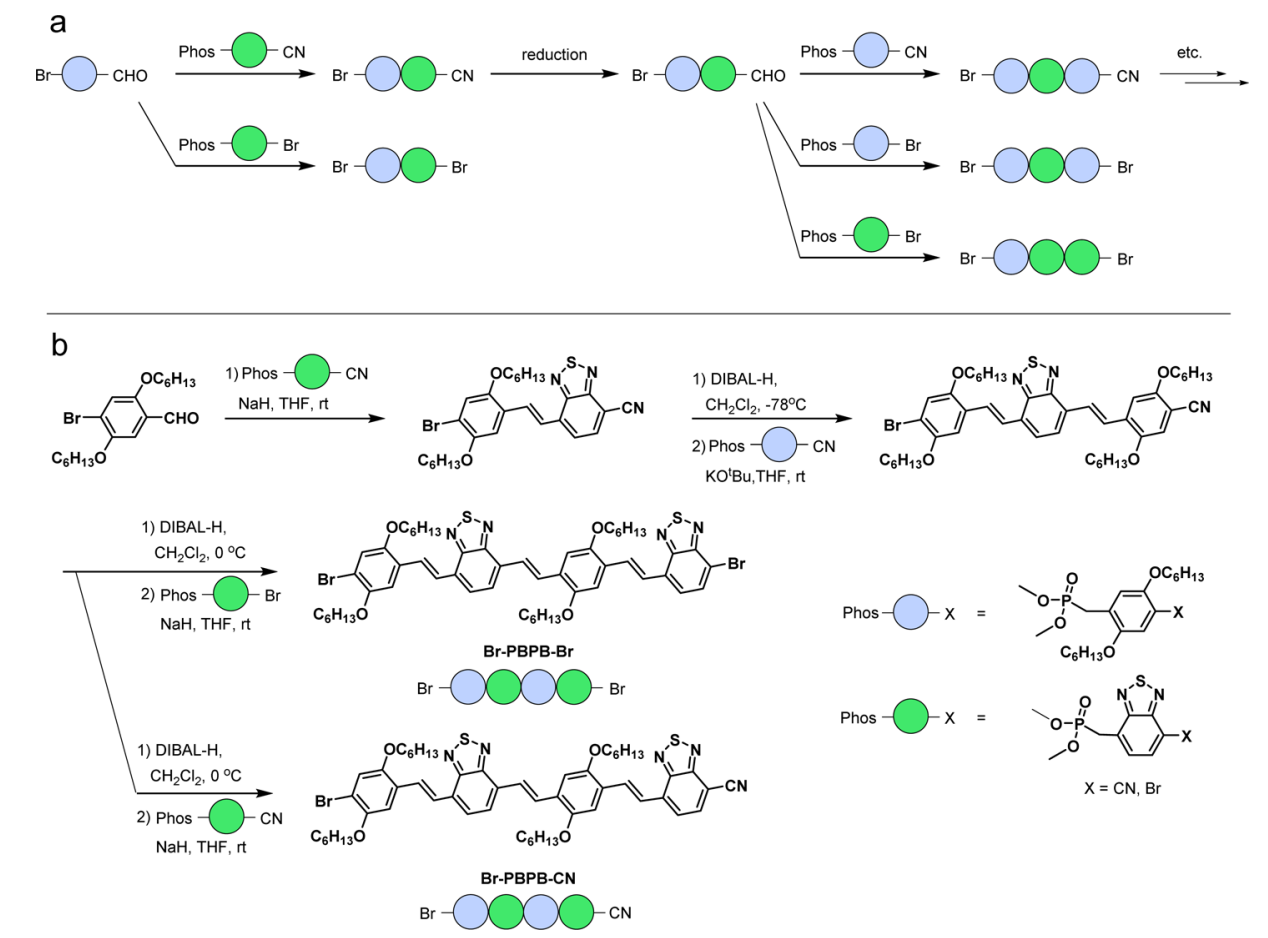

Figure 1. (a) Schematic depicting synthetic strategy,. (b) Sample synthesis of two sequenced oligomers.

Table 1. Optical and Electrochemical Data for Sequenced Oligomers

\begin{tabular}{|c|c|c|c|c|c|c|}
\hline oligomer $^{e}$ & $\lambda_{\max }^{a \text { abs } a} / \mathrm{nm}$ & $\lambda_{\max }^{e m} a / n m$ & $E_{\text {gap }}^{\text {opt } b} / \mathrm{V}$ & $E_{\text {peak }}^{\text {ox }}{ }^{c} / \mathrm{V}$ & $E_{\text {peak }}^{\text {red }} c / \mathrm{V}$ & $\Delta E_{\text {gap }}^{\mathrm{ec} d} / \mathrm{eV}$ \\
\hline Br-PB-Br & 432 & 576 & 2.97 & 1.05 & -1.50 & 2.55 \\
\hline Br-PB-CN & 450 & 593 & & - & - & - \\
\hline C8-PB-C8 & 429 & 585 & 2.98 & - & - & - \\
\hline $\mathrm{Br}-\mathrm{BPB}-\mathrm{Br}$ & 479 & - & - & - & - & - \\
\hline Br-PPB-Br & 464 & 628 & 2.29 & 0.77 & -1.44 & 2.21 \\
\hline Br-PBP-Br & 476 & 594 & 2.28 & 0.89 & -1.47 & 2.36 \\
\hline Br-PBP-CN & 467 & 583 & 2.29 & - & - & - \\
\hline Br-PPB-CN & 498 & 658 & 2.14 & - & - & - \\
\hline Br-BPP-CN & 458 & 609 & 2.33 & - & - & - \\
\hline C8-BPP-C8 ${ }^{47}$ & 448 & 613 & - & - & - & \\
\hline C8-PBP-C8 ${ }^{47}$ & 489 & 618 & - & - & - & - \\
\hline Br-BPPB-Br & 493 & 639 & 2.19 & 0.65 & -1.45 & 2.10 \\
\hline Br-PBPB-Br & 507 & 613 & 2.15 & 0.75 & -1.44 & 2.19 \\
\hline Br-PBPB-CN & 523 & 702 & 2.07 & - & - & - \\
\hline Br-PPBB-Br & 508 & 637 & 2.10 & 0.71 & -1.31 & 2.02 \\
\hline Br-PPBB-CN & 530 & 707 & 1.99 & - & - & - \\
\hline Br-PBBP-Br & 512 & 595 & 2.13 & 0.82 & -1.31 & 2.13 \\
\hline
\end{tabular}

${ }^{a}$ Measured in $\mathrm{CHCl}_{3}\left(1.0 \times 10^{-5} \mathrm{M}\right)$; ${ }^{b}$ Determined at the onset of absorption spectra; ${ }^{c}$ Potential vs $\mathrm{Ag} / \mathrm{Ag}+, 240 \mu \mathrm{M}$ in $0.1 \mathrm{M} \mathrm{Bu}_{4} \mathrm{NPF}_{6}$ in THF; ${ }^{d}$ Determined as $\Delta E_{\text {gap }}^{\text {ec }}=\mathrm{e}\left(E_{\text {peak }}^{\text {ox }}-E_{\text {peak }}^{\text {red }}\right) ;{ }^{e} \mathrm{~B}$ : benzothiadiazole unit. P: 2,5-dihexylalkoxy substituted phenylene units. Br: bromo end group, CN: cyano end group; $\mathrm{C} 8:-\mathrm{CH}_{2}\left(\mathrm{CH}_{2}\right)_{5} \mathrm{CH}=\mathrm{CH}_{2}$.

investigation of thiophene- and selenophene-based conjugated polymers with gradient sequence, block, and random structures. $^{36}$ The influence of sequence on properties, particularly photophysical properties, was also established by Noonan and co-workers for a series of copolymers comprising sequences of furan, thiophene, and selenophene. ${ }^{40}$

These intriguing reports have inspired us to further understand the influence of sequence on copolymer properties through the systematic preparation, characterization, and modeling of sequenced conjugated oligomers and polymers. In a prior study, we synthesized a series of oligomers using two monomers-an unsubstituted and a dialkoxy-substituted phenylenevinylene-and discovered that the sequence strongly affected oxidation potentials, HOMO energies, and band gaps of these otherwise largely identical oligomers. ${ }^{14}$ In tetramers, we found that the optical band gaps could be tuned over a range of $0.2 \mathrm{eV}$, based only on sequence and the end groups, despite that both monomers are electronically similar.

In the present investigation, we further explore the effect of sequence with two electronically different monomers: dialkoxysubstituted phenylenevinylene (electron-rich, P) and benzothiadiazole vinylene (electron-poor, B). While these monomers have been widely investigated for applications in OLED and solar cells, ${ }^{41-46}$ the effect of sequencing these monomers have 


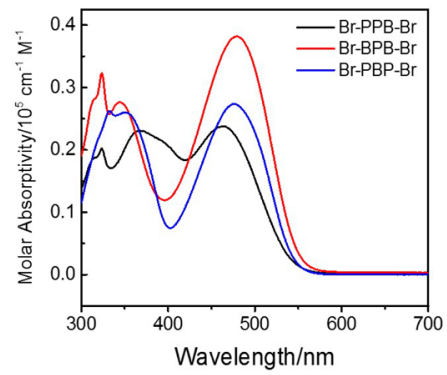

a

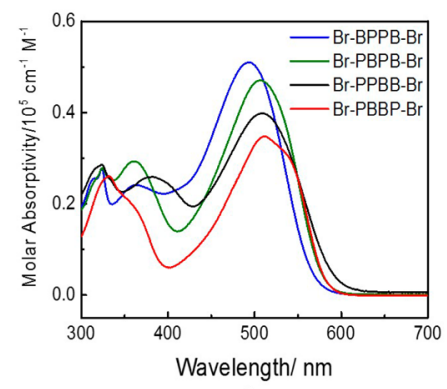

d

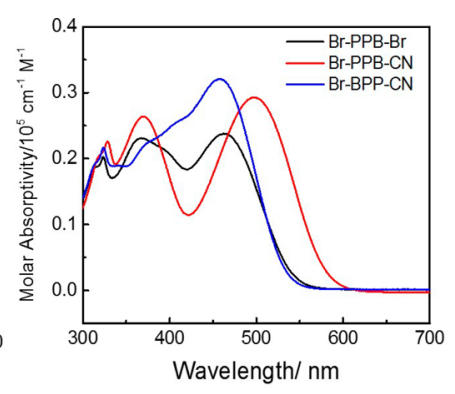

b

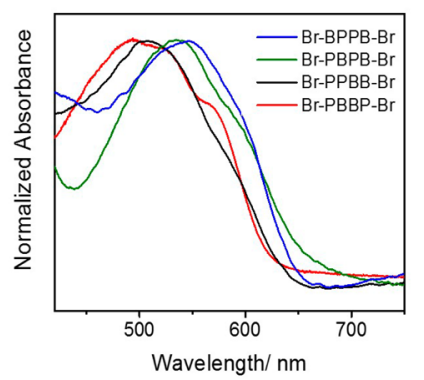

e

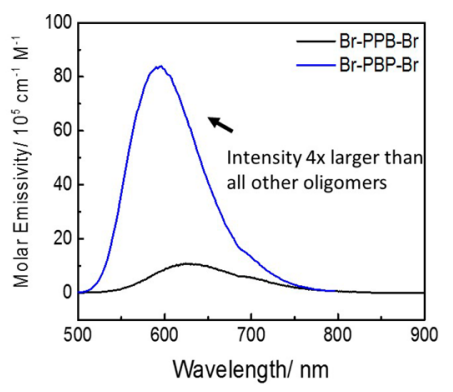

C

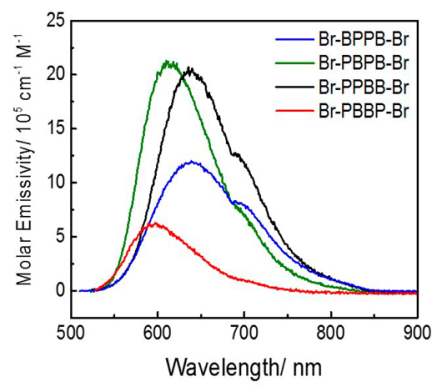

f

Figure 2. Absorption and emission spectra: (a) absorption spectra for all dibromo trimers in chloroform $\left(1.0 \times 10^{-5} \mathrm{M}\right)$; (b) absorption spectra for PPB trimers bearing cyano and bromo end groups in chloroform $\left(1.0 \times 10^{-5} \mathrm{M}\right) ;(\mathrm{c})$ emission spectra for selected trimers in chloroform $\left(1.0 \times 10^{-5}\right.$ $\mathrm{M})$; (d) absorption spectra for all dibromo tetramers in chloroform $\left(1.0 \times 10^{-5} \mathrm{M}\right)$; (e) film absorption spectra of dibromo tetramers, cast from chloroform solution; (f) emission spectra for dibromo tetramers in chloroform $\left(1.0 \times 10^{-5} \mathrm{M}\right)$.

not been probed outside of our preliminary communication. ${ }^{47}$ In that early comparative study, we characterized two trimers prepared from $\mathbf{P}$ and $\mathbf{B}$ units and incorporated these trimers into polymeric structures. Herein, we extend our earlier study to tetrameric oligomers, and comprehensively investigate the effect of sequence and end groups on optoelectronic properties of these materials and their performance in bulk heterojunction solar cells.

\section{RESULTS}

Synthesis. A series of conjugated oligomers with varying sequences were prepared by connecting two units, benzothiadiazole (B) and 2,5-dihexylalkoxy-substituted phenylene (P), with vinylene linkers (Figure 1a). The oligomers comprised dimers, trimers and tetramers, based on the total number of $\mathbf{P}$ / $\mathbf{B}$ units, and bore either two bromo $(\mathbf{B r})$ end groups, one $\mathbf{B r}$ and one cyano $(\mathbf{C N})$ end group, or two $\alpha$-olefinic alkyl groups (C8). Species with reactive end groups including aldehyde (CHO) and dimethyl phosphonate (Phos) were also prepared as synthetic intermediates. Oligomers are named throughout by listing their $\mathbf{P} / \mathbf{B}$ sequence and end groups, e.g., Br-PB-CN.

Oligomers were assembled from a set of building blocks by sequential Horner-Wadsworth-Emmons (HWE) reactions as described previously (Figure 1b). ${ }^{47}$ Nitrile-terminated oligomers were prepared for subsequent additions by reductive conversion to the aldehyde functionality. Using this approach, two dimers, six trimers and six tetramers were prepared (Table 1).

Optical and Electronic Properties. The optical and electrochemical properties of the sequenced oligomers were determined and are presented in Table 1 and Figures 2 and 3. As expected, the absorption maxima show a red-shift with increasing oligomer length: dimers (429-450 nm), trimers $(458-479 \mathrm{~nm})$, and tetramers $(490-530 \mathrm{~nm})$. Emissions likewise shift toward longer wavelengths; and band gaps, both a
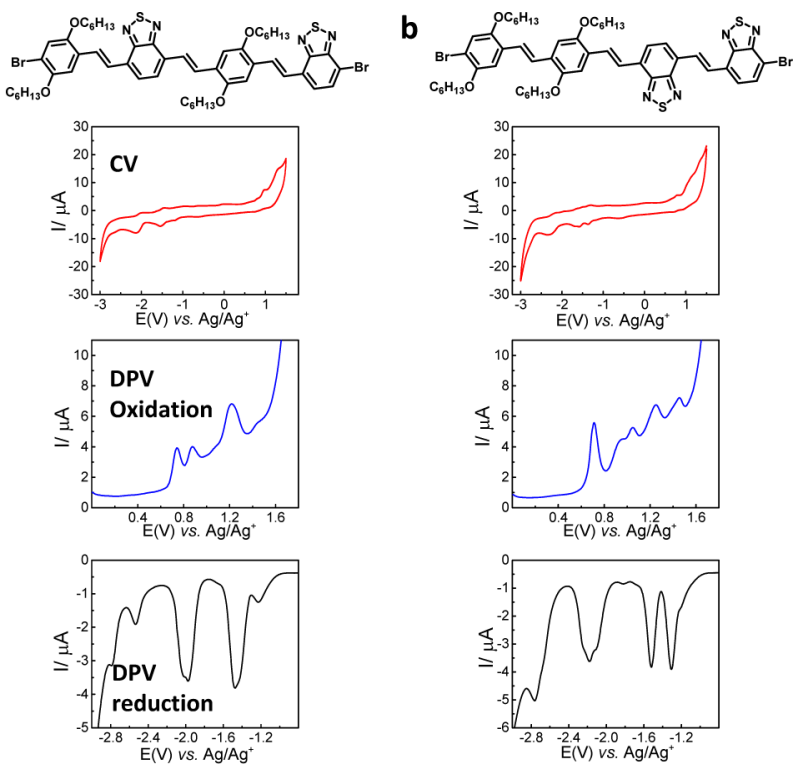

Figure 3. Sample cyclic voltammograms and differential pulse voltammograms of (a) Br-PBPB-Br and (b) Br-PPBB-Br.

optical and electrochemical, narrow as expected with increasing conjugation length.

Although it is challenging to deconvolute the end group effects from the sequence effects in these oligomeric structures, we were able, with such a rich library of oligomers, to understand the trends and focus our attention on bromo end groups, which have only a minor impact on the electronic properties. In considering end group effects, it is important to understand that terminal units are distinct from internal ones due to the neighboring free space, independent of the identity of the functional end group. As tetramers comprise 50\% terminal monomers and $50 \%$ internal monomers, many 
changes in sequence will necessarily involve changes in the terminal monomers as well.

Consistent with our earlier studies on sequenced phenylenevinylene oligomers, the effect of the unsaturated, electronwithdrawing cyano substituent was profound and depended significantly on the identity of the terminal monomer to which it was attached. Comparing two oligomers that have the same inherent sequence, PPB, but reversed end groups, Br-BPP-CN vs Br-PPB-CN (=CN-BPP-Br), it was observed that the $\lambda_{\max }$ red-shifted nearly $40 \mathrm{~nm}$. Adding the cyano end group to a $\mathbf{B}$ monomer created a much stronger electron-withdrawing unit. Oligomers with $\mathbf{- C N}$ attached to a $\mathbf{P}$ monomer absorbed at a slightly higher energy than the other PPB analogues studied. Oligomers with the - $\mathbf{C N}$ located on a B-monomer absorbed at lower energies than the dibromo-terminated sequences (e.g., Br-PPB-CN and Br-PBPB-CN)

Bromo and $\mathbf{C 8}$ end groups appeared to exert only a modest influence on the optical properties, especially when compared to the highly perturbing - $\mathbf{C N}$. That being said, the same pattern of dependence on the identity of the terminal monomer which was noted for - $\mathrm{CN}$ was also observed for these two end groups. The $\mathrm{C8}\left(\mathrm{C} 8=-\left(\mathrm{CH}_{2}\right)_{6} \mathrm{CH}=\mathrm{CH}_{2}\right)$ group would be expected to be only a mild $\sigma$-donor while the bromo group should be modestly $\sigma$-withdrawing and $\pi$-donating. In solution, a red shift of $13 \mathrm{~nm}$ was observed when changing the electronwithdrawing $\mathbf{B r}$ to an electron-donating $\mathbf{C 8}$ on $\mathbf{P}$ units in the PBP analogues, Br-PBP-Br $\left(\lambda_{\max }=476 \mathrm{~nm}\right)$ and C8-PBP-C8 $\left(\lambda_{\max }=489 \mathrm{~nm}\right)$. The effect of the interaction of the end group with the attached monomer can also be seen in the comparison of Br-PB-Br $\left(\lambda_{\max }=429 \mathrm{~nm}\right)$ vs C8-PB-C8 $\left(\lambda_{\max }=432 \mathrm{~nm}\right)$ and Br-PPB-Br $\left(\lambda_{\max }=464 \mathrm{~nm}\right)$ vs C8-PPB-C8 $\left(\lambda_{\max }=448\right.$ $\mathrm{nm})$. On the basis of these data, we hypothesize that when a $\mathbf{B r}$ attached to a $\mathbf{B}$ unit is replaced with a $\mathbf{C 8}$, e.g., $\mathbf{B r}-\mathbf{P B}-\mathbf{B r}$ to $\mathbf{B r}$ PB-C8, the blue shift of the $\lambda_{\max }$ is partly canceled by the red shift due to the $\mathbf{C 8}$ substitution of the $\mathbf{B r}$ on the $\mathbf{P}$ unit, e.g., $\mathbf{B r}$ PB-Br to C8-PB-Br. As these effects were relatively modest relative to those observed with the $-\mathbf{C N}$ group, we elected to focus our sequence comparison studies on the dibromosubstituted oligomers.

In examining the Br-terminated oligomers, we did indeed find evidence for sequence effects in both the trimer and tetramer series (Figure 4). Focusing only on the two trimers with the same $2: 1$ ratio of $\mathbf{P}: \mathbf{B}$ and bromo end groups, Br-PBP$\mathrm{Br}$ and Br-PPB-Br , differences in absorption maxima $(\Delta=10$ $\mathrm{nm})$, oxidation potential $(\Delta=0.12 \mathrm{~V})$, and electrochemical gap $(\Delta=0.15 \mathrm{~V})$ were observed. The reduction potentials were, however, similar $(\Delta=0.03 \mathrm{~V})$, suggesting that they are determined primarily by the single $\mathbf{B}$ unit. It should be noted that $\mathbf{B r}-\mathbf{P P B}-\mathbf{B r}$, which is the name used throughout this paper, could also be written as Br-BPP-Br.

Unambiguous sequence effects are also clearly seen in the dibromo-terminated tetramer series all of which have the same 1:1 P:B ratio. Most persuasively, the two bromo-terminated tetramers Br-PPBB-Br and $\mathbf{B r}-\mathbf{P B P B}-\mathbf{B r}$, exhibited the largest difference in the magnitude of their electrochemical gaps $(0.17$ $\mathrm{V})$. Since both of these oligomers have exactly one $\mathbf{P}-\mathrm{Br}$ and one $\mathrm{B}-\mathrm{Br}$ interaction, the difference must be attributed to sequence alone. Br-PPBB-Br exhibited both a less positive reduction and less negative oxidation potential than the alternating sequence isomer (Br-PBPB-Br). In examining the other two oligomers in the series, it became clear the presence of a BB-pairing defines the reduction potential: both Br-PPBB$\mathrm{Br}$ and $\mathrm{Br}-\mathrm{PBBP}-\mathrm{Br}$ were reduced at $-1.31 \mathrm{~V}$. The oligomers

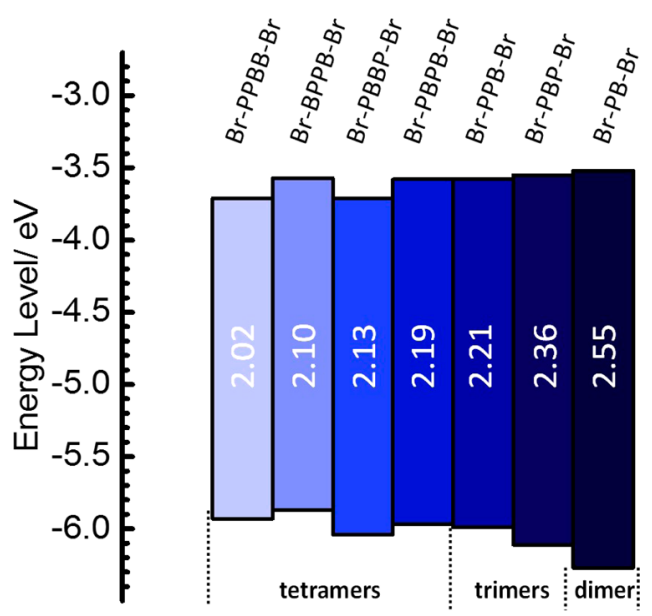

Figure 4. Electrochemical redox potentials and band gaps of sequenced oligomers, expressed relative to vacuum. Electrochemical band-gaps are indicated in $\mathrm{eV}$. The color gradient is for illustration purposes only.

Br-BPPB-Br and Br-PBPB-Br exhibited more negative reduction potentials of -1.45 and $-1.46 \mathrm{~V}$, respectively. The trend in oxidation potentials appears to depend more on the distance between $\mathbf{P}$ units. Those oligomers with a PP-pairing, Br-BPPB-Br and Br-PPBB-Br, exhibited lower oxidation potentials than those with separated $\mathbf{P}$ units. The trend is gradual, however, not binary as was the case for the reduction potentials vs BB-pairings.

We also observe some intriguing sequence effects in the solution phase absorption and emission spectra, especially in absorption/emission intensities. For the trimers with a 2:1 P:B ratio, the absorption intensities at $10^{-5} \mathrm{M}$ in chloroform are similar (ca. $0.3 \times 10^{5} \mathrm{~cm}^{-1} \mathrm{M}^{-1}$ ) but the emission intensities are dramatically different (Figure 2e). In particular, the intensity of the emission for Br-PBP-Br of $80 \times 10^{5} \mathrm{~cm}^{-1}$ $\mathrm{M}^{-1}$ is at least $4 \times$ larger than that for all other oligomers characterized. Within the $1: 1 \quad \mathbf{P}: \mathbf{B}$ tetramer series, the absorption intensities are modestly different (range 0.35-0.5 $\times 10^{5} \mathrm{~cm}^{-1} \mathrm{M}^{-1}$ ) with Br-BPPB-Br $>$ Br-PBPB-Br $>$ BrPPBB-Br > Br-PBBP-Br which is inversely related to the increase in absorption wavelength. The emission intensities for these tetramers exhibited larger differences (range 5-20 $\times 10^{5}$ $\mathrm{cm}^{-1} \mathrm{M}^{-1}$ ) but follow the order Br-PBPB-Br $\approx$ Br-PPBB-Br $>$ Br-BPPB-Br > Br-PBBP-Br which does not appear to correlate with the changes in emission wavelength. These differences in intensity cannot be simply explained as the trends differ between the trimeric and tetrameric oligomers. For example, the two oligomers with the highest degree of quenching, $\mathrm{Br}$ PPB-Br and Br-PBBP-Br, are dissimilar in both symmetry and end group attachment. The lack of correlation between the trimer and tetramer systems suggests that these differences could only be explained by a full photophysical study which lies beyond the scope of the current work.

Absorption data for thin films were also collected for those tetramers that were selected for incorporation in devices (Figure 2c). The $\lambda_{\max }$ of films cast from chloroform solutions followed the trend Br-BPPB-Br $\left(\lambda_{\max }=546 \mathrm{~nm}\right)>$ Br-PBPB$\operatorname{Br}\left(\lambda_{\max }=536 \mathrm{~nm}\right)>$ Br-PPBB-Br $\left(\lambda_{\max }=510 \mathrm{~nm}\right)>$ Br$\operatorname{PBBP}-\mathrm{Br}\left(\lambda_{\max }=494 \mathrm{~nm}\right)$. Notably this trend is opposite to their absorption maxima in solution Br-BPPB-Br $\left(\lambda_{\max }=493\right.$ $\mathrm{nm})<\operatorname{Br}-\mathrm{PBPB}-\mathrm{Br}\left(\lambda_{\max }=507 \mathrm{~nm}\right)<\operatorname{Br}-\mathrm{PPBB}-\mathrm{Br}\left(\lambda_{\max }=\right.$ $508 \mathrm{~nm})<$ Br-PBBP-Br $\left(\lambda_{\max }=512 \mathrm{~nm}\right)$ (Figure $\left.2 \mathrm{~b}\right)$. The fact 
that these sequences exhibit a different pattern of absorption in the solid state suggests that the interchain interactions and short-range order are also sequence-dependent, with Br-BPPB$\mathrm{Br}$ exhibiting the largest red-shift and potentially the highest degree of aggregation. Also consistent is the fact that we observe larger sequence-based differences in the $\lambda_{\max }$ absorptions in the solid state $(52 \mathrm{~nm})$ than in solution (19 $\mathrm{nm})$.

A selection of these oligomers were incorporated into solar cells to further understand the impact of sequence on the device performance (Figure 5, Table 2). On the basis of

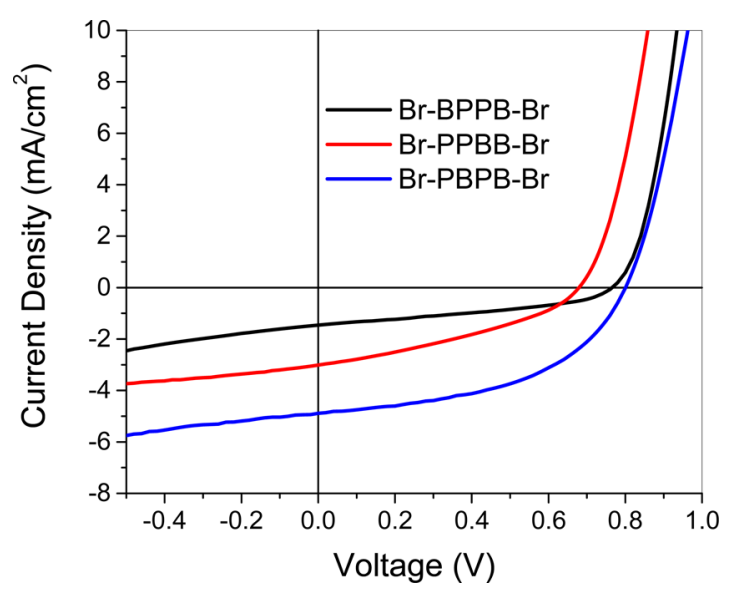

Figure 5. Representative $J-V$ output of photovoltaic devices based on oligomers.

literature reports of related molecules and the relatively short conjugation lengths, we would only expect modest power conversion efficiencies for these materials; ${ }^{5}$ however, we hypothesized that any observed differences in the devicerelated characteristics would offer insight into the effect of sequence on the multiplicity of properties that contribute to device performance. To investigate these properties, bulk heterojunction $(\mathrm{BHJ})$ solar cells were fabricated with the configuration of ITO/PEDOT:PSS/oligomer:PC ${ }_{61} \mathrm{BM}$ (1:1)/ $\mathrm{Ca} / \mathrm{Al}$ for selected oligomers: Br-PBP-Br, Br-PPB-Br, BrPBPB-Br, Br-BPPB-Br, and Br-PPBB-Br. The tetramer, BrPBBP-Br was not included due to synthetic challenges (extremely poor solubility of intermediates) that precluded the preparation of the quantities necessary for these studies.

The first sequence-based difference was observed in the trimer series with the same 2:1 P:B ratio (Table 2). Br-PBP-Br did not give any measurable performance in the solar cell, while Br-PPB-Br exhibited a small but reproducible power conversion efficiency (PCE) of $0.28 \%$. PPB analogues with different end groups (Br-BPP-CN and Br-PPB-CN) were also studied (Table S1). The differences in PCE $(0.28 \%-0.37 \%)$ between all three PPB analogues were negligible, therefore no reliable conclusion about end group effects on solar cell performance can be drawn from these data. Increasing the conjugation length from trimer to tetramer increased the overall performance of the materials as would be expected. ${ }^{48}$

For the 1:1 P:B ratio tetramers, the measured efficiencies ranged from $0.47 \%$ for $\mathrm{Br}-\mathrm{BPPB}-\mathrm{Br}$ to $1.86 \%$ for $\mathrm{Br}-\mathrm{PBPB}-\mathrm{Br}$, a difference of $\sim 3 \times$. Devices prepared with $\mathbf{B r}-\mathbf{P P B B}-\mathbf{B r}$ exhibited an intermediate PCE of $0.79 \%$. Please note that all three devices had similarly thin active layers $(\sim 85 \mathrm{~nm})$ such that the observed device performance can be directly correlated with the optoelectronic properties of these oligomers. To provide more insight into the reasons for these differences, the hole mobilities of the $\mathrm{BHJ}$ blends were measured via the space charge limited current (SCLC) method by fabricating hole-only devices with the structure ITO/PEDOT:PSS/oligomer: $\mathrm{PC}_{61} \mathrm{BM}(1: 1) / \mathrm{MoO}_{3} / \mathrm{Al}$ (Table S2). The hole mobilities follow the trend Br-BPPB-Br $\left(5.94 \times 10^{-5} \mathrm{~cm}^{2} \mathrm{~V}^{-1} \mathrm{~s}^{-1}\right)>\mathrm{Br}$ PBPB-Br $\left(2.87 \times 10^{-5} \mathrm{~cm}^{2} \mathrm{~V}^{-1} \mathrm{~s}^{-1}\right)>$ Br-PPBB-Br $(1.58 \times$ $\left.10^{-5} \mathrm{~cm}^{2} \mathrm{~V}^{-1} \mathrm{~s}^{-1}\right)$. The relatively low hole mobilities are consistent with the modest PCEs exhibited by these oligomers; high fill factors are normally associated with mobility values of $\sim 10^{-3} \mathrm{~cm}^{2} \mathrm{~V}^{-1} \mathrm{~s}^{-1}$. $49-52$

Film topologies of neat tetramer films and photoactive layers (tetramers $/ \mathrm{PC}_{61} \mathrm{BM}$ ) in solar cells were further characterized by tapping mode atomic force microscopy (AFM). As shown in Figure S13, distinct topologies in spin-cast neat films of three tetramers were observed. Particularly, the root mean squared (RMS) height of the neat Br-PBPB-Br film is much smaller than that of the other two sequences $(0.843 \mathrm{~nm}$ vs 14.2 and $17.2 \mathrm{~nm})$. However, no obvious topology differences in photoactive layers were observed between sequences (Figure S14).

Computational Approach. Computational methods provide a fast and relatively inexpensive mechanism to screen optoelectronic properties of $\pi$-conjugated materials. Several studies have found a high degree of correlation between density functional theory (DFT) computed orbital eigenvalues, vertical ionization potentials and electron affinities, ${ }^{5,54}$ though these calculations yield nonphysical results. ${ }^{55,56}$ In addition, DFT calculations provide accurate predictions of optical band gaps. ${ }^{57}$ In solution electrochemistry, redox potentials can be predicted based on the free energy change. ${ }^{58,59}$ The adiabatic difference in total energy between the neutral and positively or negatively charged systems $(\triangle \mathrm{SCF})$ provides oxidation or reduction potentials, respectively.

Since our objective was to reliably and accurately screen for targeted properties of sequenced oligomers, we chose to extend these regression techniques by use of a "consensus model" to minimize both systematic and random errors, i.e., to improve accuracy and correlation. The consensus model used here combines two different computational predictions of an

Table 2. Device Characteristics of BHJ Solar Cell with Oligomers:PCBM (1:1)

\begin{tabular}{|c|c|c|c|c|c|}
\hline oligomers & thickness/nm & $J_{\mathrm{sc}}^{a} / \mathrm{mA} \cdot \mathrm{cm}^{-2}$ & $V_{\mathrm{oc}}^{b} / \mathrm{V}$ & $\mathrm{FF}^{c} / \%$ & $\mathrm{PCE}^{d} / \%$ \\
\hline Br-PBP-Br & 131 & $0.02 \pm 0.01$ & $0.455 \pm 0.109$ & $27.3 \pm 1.4$ & $0.00 \pm 0.00$ \\
\hline Br-PPB-Br & 152 & $0.96 \pm 0.04$ & $0.824 \pm 0.009$ & $35.1 \pm 0.4$ & $0.28 \pm 0.01$ \\
\hline Br-BPPB-Br & 85 & $1.45 \pm 0.11$ & $0.770 \pm 0.016$ & $41.2 \pm 5.8$ & $0.47 \pm 0.10$ \\
\hline Br-PPBB-Br & 84 & $3.16 \pm 0.16$ & $0.717 \pm 0.075$ & $34.5 \pm 1.7$ & $0.79 \pm 0.15$ \\
\hline Br-PBPB-Br & 89 & $4.85 \pm 0.42$ & $0.768 \pm 0.036$ & $49.4 \pm 2.9$ & $1.85 \pm 0.26$ \\
\hline
\end{tabular}

${ }^{a} J_{\mathrm{sc}}$ : short circuit current. ${ }^{b} V_{\mathrm{oc}}$ : open circuit voltage. ${ }^{c} \mathrm{FF}$ : fill factor. ${ }^{d} \mathrm{PCE}$ : power conversion efficiency. 
experimental property using multivariate regression, e.g., oxidation potential. For redox potentials, calculated HOMO or LUMO eigenvalues and adiabatic total energy differences $(\triangle \mathrm{SCF})$ were both used, and to predict optical absorption energies, ZINDO and time-dependent DFT (TDDFT) methods were combined with the HOMO-LUMO difference.

The computational method was parametrized on the trimer and tetramer compounds that were synthesized. The electronic properties of all possible dimer, trimer and tetramer sequences were then predicted based on the derived models. (Table 3)

Table 3. Consensus Model-Predicted Oxidation, Reduction, and Gap Energies for Dimers, Trimers, and Tetramers

\begin{tabular}{|c|c|c|c|}
\hline oligomer & predicted $E_{\text {peak }}^{\text {ox }} / \mathrm{V}$ & predicted $E_{\text {peak }}^{\text {red }} / \mathrm{V}$ & $\Delta E_{\text {gap }}^{\text {comp }} / \mathrm{eV}$ \\
\hline $\mathrm{Br}-\mathrm{PB}-\mathrm{Br}^{a}$ & 1.06 & -1.47 & 2.55 \\
\hline Br-PB-CN & 1.20 & -1.53 & - \\
\hline $\mathrm{Br}-\mathrm{BP}-\mathrm{CN}$ & 1.27 & -1.43 & - \\
\hline $\mathrm{Br}-\mathrm{BPB}-\mathrm{Br}$ & 0.84 & -1.43 & 3.23 \\
\hline Br-PBP-Br & 0.82 & -1.44 & 3.36 \\
\hline Br-PBP-CN & 0.96 & -1.41 & 3.31 \\
\hline Br-PPB-Br ${ }^{a}$ & 0.81 & -1.46 & 3.34 \\
\hline Br-PPB-CN & 0.83 & -1.45 & 3.12 \\
\hline Br-BPP-CN & 0.99 & -1.44 & 3.41 \\
\hline Br-PBB-CN & 0.96 & -1.40 & 3.09 \\
\hline Br-BPB-CN & 0.94 & -1.42 & 3.13 \\
\hline Br-BPPB-Br & 0.66 & -1.44 & 3.09 \\
\hline Br-PBPB-Br ${ }^{a}$ & 0.76 & -1.41 & 3.07 \\
\hline Br-PBPB-CN & 0.63 & -1.41 & 3.11 \\
\hline Br-PPBB-Br ${ }^{a}$ & 0.71 & -1.36 & 3.05 \\
\hline Br-PPBB-CN & 0.80 & -1.40 & 3.11 \\
\hline Br-PBBP-Br & 0.76 & -1.37 & 3.10 \\
\hline Br-PBBP-CN & 0.70 & -1.38 & 3.11 \\
\hline Br-BPPB-CN & 0.65 & -1.44 & 3.19 \\
\hline Br-BPBP-CN & 0.63 & -1.41 & 3.11 \\
\hline Br-BBPP-CN & 0.64 & -1.41 & 3.04 \\
\hline
\end{tabular}

When palindromic sequences were examined (i.e., Br-PPB-Br and Br-BPP-Br), energy differences in predicted oxidation potentials $(\sim 0.04 \mathrm{~V})$, reduction potentials $(\sim 0.01 \mathrm{~V})$, and optical absorption energies $(\sim 0.03 \mathrm{eV})$ were observed due to conformational differences. ${ }^{46}$

In general, computed and experimental parameters show only small residual errors compared to their experimental counterparts (Figure 6). We find mean unsigned errors (MUE) between computed and experimental parameters after the linear regression analysis to be very low, with $0.03 \mathrm{~V}$ MUE for oxidation potentials $\left(R^{2}=0.70\right), 0.04 \mathrm{~V}$ MUE for reduction potentials $\left(R^{2}=0.77\right)$, and $9 \mathrm{~nm}$ MUE for optical absorption maxima $\left(R^{2}=0.89\right)$. The high degree of agreement is not surprising because the sequenced oligomers define a closely analogous series, and the consensus technique minimizes systematic and random errors. With the limited number of experimental electrochemical measurements, the correlation coefficient $R^{2}$ is deceivingly poor. Orbital shapes for each of the oligomers prepared were computed and are plotted in Figure 7.

As the MUEs between experiment and computed properties were low, we extended the calculations to longer oligomers to explore the role of sequence and $\mathbf{P P} / \mathbf{B B}$ pairings. The electronic structure of all hexamers with 50:50 B:P ratios were computed (Table 4, Table S4). Since conformational effects can be significant, we again computed low energy
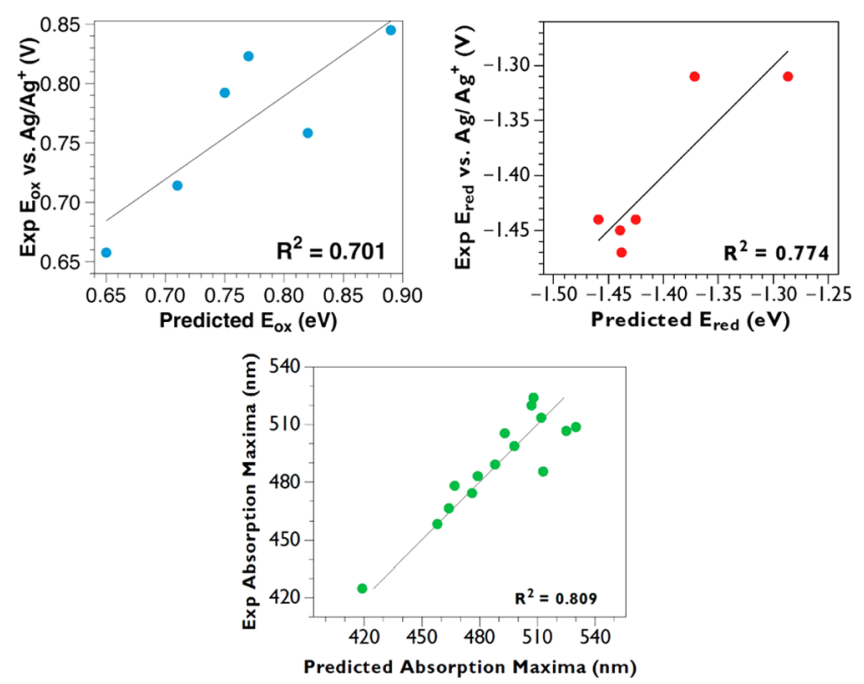

Figure 6. Correlations between computed first oxidation potential, first reduction potential, and optical excitation energies with their experimental counterparts. Note that, for all predicted properties, a consensus model of two predictors yields small residual errors compared to their experimental counterparts.

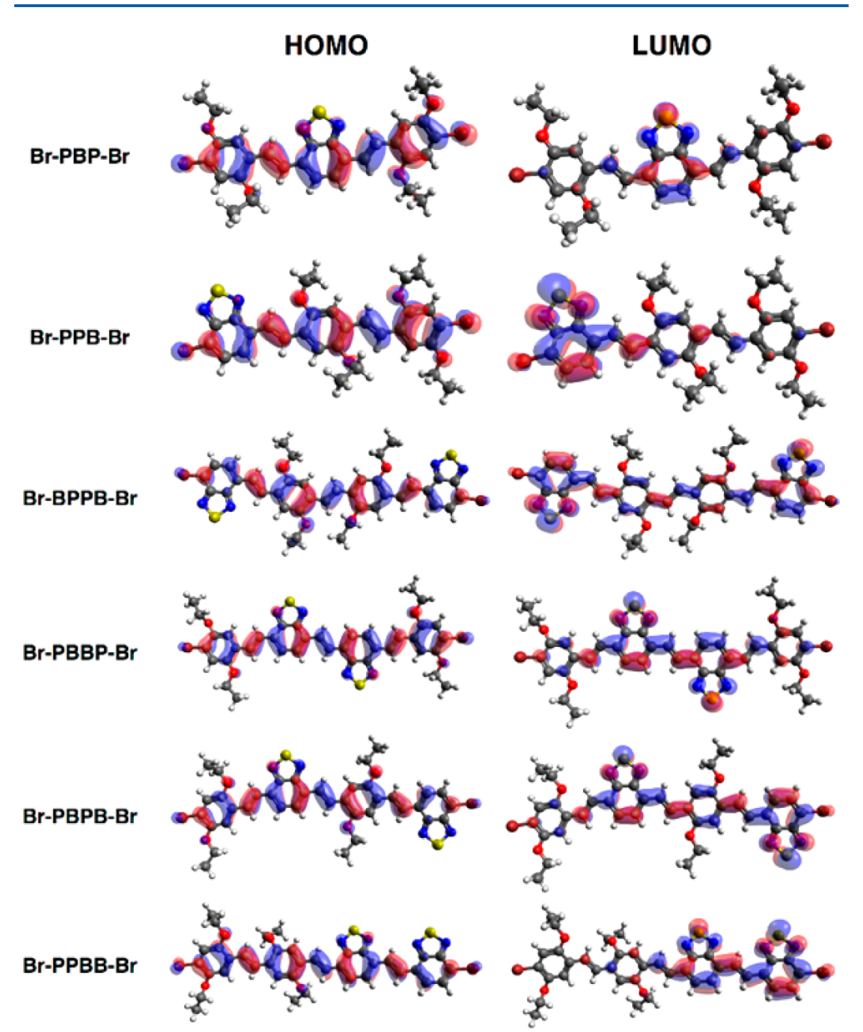

Figure 7. Computed orbital shapes for trimers and tetramers studied.

conformers for both "palindromic" orders (e.g., Br-PBPBPB$\mathrm{Br}$ and Br-BPBPBP-Br) to estimate the variations due to conformational local minima. We find the variation to be $\sim 0.1$ $\mathrm{eV}$, on par with other estimates. ${ }^{46}$

\section{DISCUSSION}

There are notable but not surprising trends in the coupling of the end groups to $\mathbf{P}$ vs $\mathbf{B}$ terminal units. When an electronwithdrawing end group is attached to the acceptor $\mathbf{B}$ units, the absorption maximum shifts to the red. In contrast, a blue shift is 
Table 4. Computed HOMO, LUMO, and Gap Eigenvalues for Hexamers

\begin{tabular}{cccc} 
oligomer & $\begin{array}{c}\text { computed } \\
\mathrm{HOMO}^{a} / \mathrm{eV}\end{array}$ & $\begin{array}{c}\text { computed } \\
\mathrm{LUMO}^{a} / \mathrm{eV}\end{array}$ & $\Delta E_{\text {gap }}^{\text {com } a} / \mathrm{eV}$ \\
Br-PPPBBB-Br & -4.79 & -2.99 & 1.80 \\
Br-PPBPBB-Br & -4.80 & -2.91 & 1.89 \\
Br-PBPPBB-Br & -4.81 & -2.87 & 1.94 \\
Br-BPPPBB-Br & -4.77 & -2.82 & 1.95 \\
Br-BPBBPP-Br & -4.81 & -2.88 & 1.93 \\
Br-BPPBPB-Br & -4.83 & -2.74 & 2.09 \\
Br-BPPBBP-Br & -4.70 & -2.78 & 1.91 \\
Br-PBBBPP-Br & -4.86 & -3.01 & 1.85 \\
Br-PBPBBP-Br & -4.87 & -2.92 & 1.96 \\
Br-PBPBPB-Br & -4.66 & -2.70 & 1.96 \\
${ }_{\text {Average of values for two conformations. }}$ \\
\hline
\end{tabular}

observed when the electron-withdrawing group is attached to the donor $\mathbf{P}$ unit, although the effect is smaller in magnitude. Not surprisingly, the - CN group exhibited a larger effect than the more mildly withdrawing $\mathbf{B r}$ end group. The electrondonating C8 groups modestly increase the absorption maxima when attached to $\mathbf{P}$ units and decrease it when attached to $\mathbf{B}$ units. Overall, the $\mathbf{B r}$ group's effects were found to be sufficiently modest that sequence-based differences could be differentiated without being masked/dominated by these $\mathbf{B r}$ groups.

In examining the data, we observe that adjacent $\mathbf{P}$ units result in higher HOMO levels and adjacent $\mathbf{B}$ units result lower LUMO levels. For example the two dibromo tetramers with higher HOMO levels (lower $E^{\text {ox }}$ ) are $\mathbf{B r}$-PPBB-Br and $\mathbf{B r}$ BPPB-Br, respectively. An even more dramatic difference is seen for the LUMO levels, with Br-PPBB-Br and Br-PBBP-Br exhibiting similar and much lower LUMO levels. The smallest band gap is necessarily exhibited by the tetramer with both, i.e., Br-PPBB-Br.

In examining the calculations there are interesting finding relevant both to end group effects and to sequence effects. We observed that in longer sequenced oligomers, synthesized in silico rather than more laboriously in the lab, the role of the terminal groups is inherently lessened, and the effect of internal sequence is therefore magnified. With regard to the effects of alternation vs localized structures, we observe in these calculated structures a noticeable correlation between the number of "nodes" between $\mathbf{P}$ and $\mathbf{B}$ monomers and the computed LUMO energies of the hexamers (Figure S18), but little correlation with the HOMO energies. Since the benzothiadiazole $\mathbf{B}$ repeat is known as a strong acceptor, this suggests in longer oligomers, BB, BBB, and similar short blocks play a significant role in influencing the optoelectronic properties. Indeed, fewer nodes (i.e., longer $\mathbf{B}_{n}$ block length) result in more negative LUMO energies and consequently narrower band gaps. Consistently, our previous computational data mining to estimate a general sequence effect in hexamers suggested that acceptor block length, and not necessarily donor effects, should be the most significant factor in controlling optoelectronic properties, ${ }^{15}$ in good agreement with this work.

We note that our previous combined experimentalcomputational investigation of the sequence effect in phenylene-vinylene based oligomers also showed a similar range of electrical and optical properties for the tetramers. ${ }^{14}$ The electrochemical gaps varied by $\sim 0.2 \mathrm{eV}$ for both the series discussed herein and the previous PPV-based oligomers. Thus, despite the large difference in redox properties between the $\mathbf{B}$ and $\mathbf{P}$ monomers (i.e., a strong donor-acceptor variation), this does not translate into a larger sequence effect. These results combined with previous computational investigations suggest that sequence based effects may be easily investigated and exploited in the more synthetically accessible donor-donor polymers. $^{13}$

Complex but distinct sequence effects were also manifested in the solar cell studies of these materials. Because of the relatively short conjugation lengths of these tetramers, the PCEs of solar cells incorporating these oligomers in the photoactive layer were modest $(<2 \%)$. Nonetheless, these measurements, combined with the related hole mobility and spectroscopic studies, provide some interesting insights into how sequence can potentially be used in the design of higher performing materials. The symmetric tetramer Br-BPPB-Br showed a thin film $\lambda_{\max }$ that was $36 \mathrm{~nm}$ higher (i.e., red-shifted) than that of Br-PPBB-Br. Interestingly, the absorption maximum for all of these tetramers is red-shifted relative to that observed for a 50:50 random copolymer of the $\mathbf{P}$ and $\mathbf{B}$ monomers reported by $\mathrm{Li}$ et $\mathrm{al}^{46}$ This observation suggests that either the effective conjugation length in these random copolymers is shorter than that of the tetramers or the tetramers are packed more effectively in the solid state. The latter explanation is supported to some degree by the fact that the absorption maxima for the three tetramers follow the reverse order in solution as they do in the solid state. The mobilities also follow the same sequence-based trend as that observed for the film absorption-the oligomer Br-BPPB-Br exhibited both the largest hole mobility and the longest solidstate $\lambda_{\text {max }}$.

A close inspection of photovoltaic device characteristics of these three bromo-terminated oligomers (BPPB, PPBB and PBPB) show that the open circuit voltage $\left(V_{o c}\right)$ only varies slightly between 0.72 and $0.77 \mathrm{~V}$. Given that $V_{\text {oc }}$ is largely determined by the energy level difference between the HOMO of the donor material (oligomers in this case) and the LUMO of the acceptor material $\left(\mathrm{PC}_{61} \mathrm{BM}\right)$, the observed small difference $(\sim 0.05 \mathrm{~V})$ is consistent with the observed HOMO energy level difference among these three oligomers $(\sim 0.10$ $\mathrm{eV})$. The small difference is not surprising, since one is comparing a solution measurement $(\mathrm{CV})$ to a film measurement $\left(V_{\text {oc }}\right)$.

The short circuit current $\left(J_{\text {sc }}\right)$, on the other hand, did show a significant dependence on sequence. If we consider $\mathbf{P}$ as the "donor", and B as the "acceptor", then we have three cases that can be analyzed: BPPB (A-D-D-A) and PPBB (D-D-A$\mathrm{A})$, vs PBPB (D-A-D-A). As the $\mathrm{D}-\mathrm{A}$ alternating structure is the dominant motif in conjugated copolymers, ${ }^{12,18,60-62}$ it might not be surprising to find that the PBPB (D-A-D-A)based device gives the highest $J_{\text {sc }}$ (and highest efficiency) in the studied series. The $\mathrm{D}-\mathrm{D}-\mathrm{A}-\mathrm{A}$ motif is the second best performing sequence. The poorest performing sequence is the symmetric, BPPB (D-A-A-D) motif. This behavior is consistent with the hypothesis that a $\mathrm{D}-\mathrm{A}$ structure (i.e., typically having a strong dipole) weakens the exciton binding energy and the geminate recombination, thereby benefiting the exciton separation and charge generation. ${ }^{63-66}$ Also, consistent with this pattern, we found that the asymmetric trimer PPB gave a modest overall solar cell performance while the symmetric PBP gave no measurable response. 


\section{CONCLUSIONS}

We find that sequence is important in both solar cell performance and related properties. In addition to PCE, we observe that absorption, emission, solid-state packing, hole mobilities, and HOMO-LUMO energy levels are all sequence dependent. We also demonstrate that using calculations we can explore sequence-space to facilitate our understanding of sequence-dependent behavior.

Although we see sequence dependence, it is clear that it remains challenging to fully correlate structure with properties in these oligomers. For example, while the optical and electrochemical properties of oligomers can be readily correlated with the sequence both experimentally and computationally, the impact of sequence on the oligomerbased device characteristics is much more difficult to understand. This is not a surprise, given that it is still a grand challenge to draw such correlations even with conjugated polymers having multiple constructing units. ${ }^{67}$

Although not measured for these materials, it seems likely that other characteristics that are important to device performance, including domain size in $\mathrm{BHJ}$ blends, thermal stability, etc. will likewise exhibit sequence dependence. Particularly exciting is the potential for using sequence to engineer multiple properties simultaneously. Among sequences that exhibit a targeted intrinsic property, such as HOMOLUMO gap, a range of bulk properties could be exhibitedsome sequences might pack well while others do not. The inverse is also possible-a range of sequences could be identified that exhibit a particular morphological trait and then refined on a desired intrinsic property, such as HOMO level. Future efforts will aim to correlate intermolecular interactions, packing, film morphology, and interfacial organization with sequence effects. The results should allow for combined computational and synthetic rational design of materials that can fulfill the complex set of requirements necessary for highly efficient organic solar cells and other applications.

\section{EXPERIMENTAL SECTION}

General Materials. Br-P-CHO, Phos-P-CN, Br-P-Br, Phos-B$\mathrm{CN}$, Br-PP-CHO, Br-PB-CN, Br-PB-CHO, Br-BP-CN, Br-BP-CHO, Br-PBP-Br, C8-PBP-C8, Br-BPP-Br, and C8-BPP-C8 were synthesized as described previously. ${ }^{14,47}$ Phos-B-Br and Br-B-CHO were prepared according to the method of Jorgenson et al. ${ }^{68}$ and Lin et al., ${ }^{69}$ respectively. DIBAL-H (1.0 $\mathrm{M}$ in hexanes) was purchased from Aldrich and dispensed using air-sensitive techniques. $\mathrm{LiCl}$ was stored in a $120^{\circ} \mathrm{C}$ oven for at least $24 \mathrm{~h}$ before use. Dry THF from SigmaAldrich was used for all reactions. $\mathrm{CH}_{2} \mathrm{Cl}_{2}$ was dried by passage through an alumina-packed column. All other reagents and solvents were used as received. Column chromatography was carried out on standard grade silica gel (60 ̊ pore size, $40-63 \mu \mathrm{m}$ particle size), which was purchased and used as received.

Spectroscopy. NMR Spectroscopy. ${ }^{1} \mathrm{H}(400$ and $500 \mathrm{MHz})$ and ${ }^{13} \mathrm{C}(100,125$, and $150 \mathrm{MHz}) \mathrm{NMR}$ spectra were recorded on Bruker spectrometers. Chemical shifts were referenced to residual ${ }^{1} \mathrm{H}$ or ${ }^{13} \mathrm{C}$ signals in deuterated solvents $(7.26$ and $77.0 \mathrm{ppm}$, respectively, for $\mathrm{CDCl}_{3}$ and 5.32 and $54.0 \mathrm{ppm}$, respectively, for $\mathrm{CD}_{2} \mathrm{Cl}_{2}$ ).

Mass Spectrometry. High resolution mass spectra were recorded on EI-quadrupole or ESI-TOF instruments in the Mass Spectrometry Facility of the University of Pittsburgh. MALDI spectra were recorded on Voyager-DE PRO instrument.

Optical Spectroscopy. Solution $\left(\mathrm{CHCl}_{3}\right) \mathrm{UV} /$ vis absorption spectra were recorded on a PerkinElmer Lambda $9 \mathrm{UV} /$ vis/NIR spectrometer. UV/vis absorption spectra of films on glass substrates were recorded on an Ocean Optics HR2000+CG-UV-NIR high- resolution spectrometer. Solution $\left(\mathrm{CHCl}_{3}\right)$ emission spectra were recorded on a Varian Cary Eclipse Fluorimeter.

Electrochemistry. Cyclic voltammetry $(\mathrm{CV})$ and differential pulse voltammetry (DPV) were performed on a CHI Electrochemical Workstation Model 430a (Austin, TX) collected using a three electrode system consisting of a glassy carbon disk ( $3 \mathrm{~mm}$ dia.) as working electrode, a nonaqueous $\mathrm{Ag} / \mathrm{Ag}+$ reference electrode $(1 \mathrm{mM}$ $\mathrm{AgNO}_{3}$ in acetonitrile), and a Pt-wire as auxiliary electrode in $0.1 \mathrm{M}$ $\mathrm{Bu}_{4} \mathrm{NPF}_{6}$ in dry THF. CV were recorded at $100 \mathrm{mV} / \mathrm{s}$. DPV parameters were as follows: scan rate of $25 \mathrm{mV} / \mathrm{s}$, pulse amplitude 0.05 $\mathrm{V}$ and pulse period $0.16 \mathrm{~s}$.

Computational Methods. Each possible trimer and tetramer sequence permutation was generated with a python script from the monomer SMILES. ${ }^{70}$ An initial 3D structure was generated using Open Babel 2.3.0 $0^{71}$ (accessed through Pybel ${ }^{72}$ ) and was minimized using the MMFF94 force field $\mathrm{d}^{73-77}$ to find a low energy minima conformation. Final geometries were optimized using Gaussian $09^{78}$ with density functional theory (DFT) B3LYP/6-31G*.79,80 To compare computational results with electrochemical experiments, redox potentials were determined using a combination of orbital energies (i.e., vertical ionization potential and electron affinity) and the $\Delta$ SCF procedure, taking the adiabatic energy difference between the optimized geometries of neutral and charged species using the conductor polarizable continuum model (C-PCM) model for tetrahydrofuran (THF). ${ }^{81}$ To compare with optical absorptions, excitation energies and oscillator strengths were computed using ZINDO $^{82}$ and TDDFT using the optimized solution geometry of the neutral species using the C-PCM solvation model ${ }^{83}$ for $\mathrm{CHCl}_{3}$. Images of molecules and orbitals in the Supporting Information were prepared using Avogadro. ${ }^{84}$

\section{ASSOCIATED CONTENT}

\section{Supporting Information}

The Supporting Information is available free of charge on the ACS Publications website at DOI: 10.1021/acs.macromol.6b02215.

General methods, synthesis of sequenced oligomers, additional cyclic and differential pulse voltammograms of sequenced oligomers, additional absorption and emission spectra of sequenced oligomers, atomic force microscopy images, photovoltaic properties and hole mobilities of selected oligomers, and additional calculation results (PDF)

\section{AUTHOR INFORMATION}

\section{Corresponding Authors}

*(G.R.H.) E-mail: geoffh@pitt.edu.

*(T.Y.M.) E-mail:tmeyer@pitt.edu.

ORCID ${ }^{\circ}$

Wei You: 0000-0003-0354-1948

Geoffrey R. Hutchison: 0000-0002-1757-1980

Tara Y. Meyer: 0000-0002-9810-454X

Notes

The authors declare no competing financial interest.

\section{ACKNOWLEDGMENTS}

We thank Amy Short for help with figures. T.Y.M. and S.Z. acknowledge the NSF (CHE-1410119), I.Y.K. acknowledges the NSF (CBET-1404591), and T.Y.M., S.Z., G.R.H., and I.Y.K. acknowledge the University of Pittsburgh for financial support. N.E.B. and W.Y. were supported by the Office of Naval Research (Grant No. N000141410221). 


\section{REFERENCES}

(1) Henson, Z. B.; Mullen, K.; Bazan, G. C. Design strategies for organic semiconductors beyond the molecular formula. Nat. Chem. 2012, 4 (9), 699-704.

(2) Grimsdale, A. C.; Leok Chan, K. L.; Martin, R. E.; Jokisz, P. G.; Holmes, A. B. Synthesis of Light-Emitting Conjugated Polymers for Applications in Electroluminescent Devices. Chem. Rev. 2009, 109 (3), 897-1091.

(3) Facchetti, A. $\pi$-Conjugated Polymers for Organic Electronics and Photovoltaic Cell Applications. Chem. Mater. 2011, 23, 733-758.

(4) Yassar, A.; Miozzo, L.; Gironda, R.; Horowitz, G. Rod-coil and all-conjugated block copolymers for photovoltaic applications. Prog. Polym. Sci. 2013, 38 (5), 791-844.

(5) Mishra, A.; Bäuerle, P. Small Molecule Organic Semiconductors on the Move: Promises for Future Solar Energy Technology. Angew. Chem., Int. Ed. 2012, 51 (9), 2020-2067.

(6) Chen, Y.; Wan, X.; Long, G. High Performance Photovoltaic Applications Using Solution-Processed Small Molecules. Acc. Chem. Res. 2013, 46 (11), 2645-2655.

(7) Wang, C.; Dong, H.; Hu, W.; Liu, Y.; Zhu, D. Semiconducting $\pi$ Conjugated Systems in Field-Effect Transistors: A Material Odyssey of Organic Electronics. Chem. Rev. 2012, 112, 2208-2267.

(8) Rochat, S.; Swager, T. M. Conjugated Amplifying Polymers for Optical Sensing Applications. ACS Appl. Mater. Interfaces 2013, 5 (11), 4488-4502.

(9) Duan, L.; Hou, L.; Lee, T.-W.; Qiao, J.; Zhang, D.; Dong, G.; Wang, L.; Qiu, Y. Solution processable small molecules for organic light-emitting diodes. J. Mater. Chem. 2010, 20 (31), 6392-6407.

(10) Zhang, L.; Colella, N. S.; Cherniawski, B. P.; Mannsfeld, S. C. B.; Briseno, A. L. Oligothiophene Semiconductors: Synthesis, Characterization, and Applications for Organic Devices. ACS Appl. Mater. Interfaces 2014, 6 (8), 5327-5343.

(11) Ellinger, S.; Graham, K. R.; Shi, P.; Farley, R. T.; Steckler, T. T.; Brookins, R. N.; Taranekar, P.; Mei, J.; Padilha, L. A.; Ensley, T. R.; Hu, H.; Webster, S.; Hagan, D. J.; Van Stryland, E. W.; Schanze, K. S.; Reynolds, J. R. Donor-Acceptor-Donor-based $\pi$-Conjugated Oligomers for Nonlinear Optics and Near-IR Emission. Chem. Mater. 2011, 23 (17), 3805-3817.

(12) Roncali, J.; Leriche, P.; Blanchard, P. Molecular Materials for Organic Photovoltaics: Small is Beautiful. Adv. Mater. 2014, 26 (23), $3821-3838$

(13) O’Boyle, N. M.; Campbell, C. M.; Hutchison, G. R. Computational Design and Selection of Optimal Organic Photovoltaic Materials. J. Phys. Chem. C 2011, 115 (32), 16200-16210.

(14) Norris, B. N.; Zhang, S.; Campbell, C. M.; Auletta, J. T.; CalvoMarzal, P.; Hutchison, G. R.; Meyer, T. Y. Sequence Matters: Modulating Electronic and Optical Properties of Conjugated Oligomers via Tailored Sequence. Macromolecules 2013, 46 (4), 1384-1392.

(15) Kanal, I. Y.; Bechtel, J. S.; Hutchison, G. R. Sequence Matters: Determining the Sequence Effect of Electronic Structure Properties in $\pi$-Conjugated Polymers. ACS Symp. Ser. 2014, 1170, 379-393.

(16) Liang, Y.; Yu, L. A New Class of Semiconducting Polymers for Bulk Heterojunction Solar Cells with Exceptionally High Performance. Acc. Chem. Res. 2010, 43 (9), 1227-1236.

(17) Mei, J.; Bao, Z. Side Chain Engineering in Solution-Processable Conjugated Polymers. Chem. Mater. 2014, 26 (1), 604-615.

(18) Lu, L.; Zheng, T.; Wu, Q.; Schneider, A. M.; Zhao, D.; Yu, L. Recent Advances in Bulk Heterojunction Polymer Solar Cells. Chem. Rev. 2015, 115 (23), 12666-12731.

(19) Szarko, J. M.; Guo, J.; Rolczynski, B. S.; Chen, L. X. Current trends in the optimization of low band gap polymers in bulk heterojunction photovoltaic devices. J. Mater. Chem. 2011, 21, 7849.

(20) Zhao, X.; Zhan, X. Electron transporting semiconducting polymers in organic electronics. Chem. Soc. Rev. 2011, 40 (7), 37283743.

(21) Risko, C.; McGehee, M. D.; Bredas, J.-L. A quantum-chemical perspective into low optical-gap polymers for highly-efficient organic solar cells. Chem. Sci. 2011, 2 (7), 1200-1218.
(22) Beaujuge, P. M.; Amb, C. M.; Reynolds, J. R. Spectral Engineering in $\pi$-Conjugated Polymers with Intramolecular DonorAcceptor Interactions. Acc. Chem. Res. 2010, 43 (11), 1396-1407.

(23) Park, Y. S.; Kale, T. S.; Nam, C. Y.; Choi, D.; Grubbs, R. B. Effects of heteroatom substitution in conjugated heterocyclic compounds on photovoltaic performance: from sulfur to tellurium. Chem. Commun. 2014, 50 (59), 7964-7967.

(24) Lin, L.-Y.; Lu, C.-W.; Huang, W.-C.; Chen, Y.-H.; Lin, H.-W.; Wong, K.-T. New A-A-D-A-A-Type Electron Donors for Small Molecule Organic Solar Cells. Org. Lett. 2011, 13 (18), 4962-4965.

(25) Schulz, M. D.; Wagener, K. B. Precision Polymers through ADMET Polymerization. Macromol. Chem. Phys. 2014, 215 (20), 1936-1945.

(26) Copenhafer, J. E.; Walters, R. W.; Meyer, T. Y. Synthesis and Characterization of Repeating Sequence Copolymers of Fluorene and Methylene Monomers. Macromolecules 2008, 41 (1), 31-35.

(27) Edwardson, T. G. W.; Carneiro, K. M. M.; Serpell, C. J.; Sleiman, H. F. An Efficient and Modular Route to Sequence-Defined Polymers Appended to DNA. Angew. Chem., Int. Ed. 2014, 53 (18), $4567-4571$.

(28) Stayshich, R. M.; Meyer, T. Y. New Insights into Poly(lactic-coglycolic acid) Microstructure: Using Repeating Sequence Copolymers To Decipher Complex NMR and Thermal Behavior. J. Am. Chem. Soc. 2010, 132 (31), 10920-10934.

(29) Lutz, J.-F.; Ouchi, M.; Liu, D. R.; Sawamoto, M. SequenceControlled Polymers. Science 2013, 341 (6146), 1238149.

(30) De Bo, G.; Kuschel, S.; Leigh, D. A.; Lewandowski, B.; Papmeyer, M.; Ward, J. W. Efficient assembly of threaded molecular machines for sequence-specific synthesis. J. Am. Chem. Soc. 2014, 136 (15), 5811-5814.

(31) Li, J.; Stayshich, R. M.; Meyer, T. Y. Exploiting Sequence To Control the Hydrolysis Behavior of Biodegradable PLGA Copolymers. J. Am. Chem. Soc. 2011, 133 (18), 6910-6913.

(32) Li, J.; Rothstein, S. N.; Little, S. R.; Edenborn, H. M.; Meyer, T. Y. The Effect of Monomer Order on the Hydrolysis of Biodegradable Poly(lactic-co-glycolic acid) Repeating Sequence Copolymers. J. Am. Chem. Soc. 2012, 134 (39), 16352-16359.

(33) Rosales, A. M.; Segalman, R. A.; Zuckermann, R. N. Polypeptoids: a model system to study the effect of monomer sequence on polymer properties and self-assembly. Soft Matter 2013, 9 (35), 8400-8414.

(34) Ward, R. E.; Meyer, T. Y. o,p-Polyaniline: A New Form of a Classic Conducting Polymer. Macromolecules 2003, 36 (12), 43684373.

(35) Rowan, S. J.; Barner-Kowollik, C.; Klumperman, B.; Gaspard, P.; Grubbs, R. B.; Hillmyer, M. A.; Hutchings, L. R.; Mahanthappa, M. K.; Moatsou, D.; O’Reilly, R. K.; Ouchi, M.; Sawamoto, M.; Lodge, T. P. Discussion on "Aperiodic Copolymers. ACS Macro Lett. 2016, 5 (1), $1-3$

(36) Palermo, E. F.; McNeil, A. J. Impact of Copolymer Sequence on Solid-State Properties for Random, Gradient and Block Copolymers containing Thiophene and Selenophene. Macromolecules 2012, 45 (15), 5948-5955.

(37) Fitzner, R.; Mena-Osteritz, E.; Mishra, A.; Schulz, G.; Reinold, E.; Weil, M.; Körner, C.; Ziehlke, H.; Elschner, C.; Leo, K.; Riede, M.; Pfeiffer, M.; Uhrich, C.; Bäuerle, P. Correlation of $\pi$-Conjugated Oligomer Structure with Film Morphology and Organic Solar Cell Performance. J. Am. Chem. Soc. 2012, 134 (27), 11064-11067.

(38) Doval, D. A.; Molin, M. D.; Ward, S.; Fin, A.; Sakai, N.; Matile, S. Planarizable push-pull oligothiophenes: in search of the perfect twist. Chem. Sci. 2014, 5 (7), 2819-2825.

(39) Liang, L.; Wang, J.-T.; Xiang, X.; Ling, J.; Zhao, F.-G.; Li, W.-S. Influence of moiety sequence on the performance of small molecular photovoltaic materials. J. Mater. Chem. A 2014, 2 (37), 15396-15405.

(40) Tsai, C.-H.; Fortney, A.; Qiu, Y.; Gil, R. R.; Yaron, D.; Kowalewski, T.; Noonan, K. J. T. Conjugated Polymers with Repeated Sequences of Group 16 Heterocycles Synthesized through CatalystTransfer Polycondensation. J. Am. Chem. Soc. 2016, 138 (21), 67986804. 
(41) Yamamoto, T.; Fang, Q.; Morikita, T. New Soluble Poly(aryleneethynylene)s Consisting of Electron-Accepting Benzothiadiazole Units and Electron-Donating Dialkoxybenzene Units. Synthesis, Molecular Assembly, Orientation on Substrates, and Electrochemical and Optical Properties. Macromolecules 2003, 36 (12), 4262-4267.

(42) Lu, S.; Yang, M.; Luo, J.; Cao, Y. Photovoltaic devices based on a novel poly(phenylene ethynylene) derivative. Synth. Met. 2004, 140 (2-3), 199-202.

(43) Liu, L.; Pei, J.; Wen, S.; Li, J.; Yao, B.; Tian, W. Optimization of Polymer Solar Cells Based on the Conjugated Copolymer of Poly(phenylenevinylene-alt-4,7-diphenyl-2,1,3-benzothiadiazole) (PPDBT). Macromol. Chem. Phys. 2013, 214 (16), 1836-1844.

(44) Nguyen, T. L.; Choi, H.; Ko, S. J.; Uddin, M. A.; Walker, B.; Yum, S.; Jeong, J. E.; Yun, M. H.; Shin, T. J.; Hwang, S.; Kim, J. Y.; Woo, H. Y. Semi-crystalline photovoltaic polymers with efficiency exceeding $9 \%$ in a [similar] $300 \mathrm{~nm}$ thick conventional single-cell device. Energy Environ. Sci. 2014, 7 (9), 3040-3051.

(45) Kim, J.; Han, A. R.; Hong, J.; Kim, G.; Lee, J.; Shin, T. J.; Oh, J. H.; Yang, C. Ambipolar Semiconducting Polymers with $\pi$-Spacer Linked Bis-Benzothiadiazole Blocks as Strong Accepting Units. Chem. Mater. 2014, 26 (17), 4933-4942.

(46) Li, X.; Zhang, Y.; Yang, R.; Huang, J.; Yang, W.; Cao, Y. Novel saturated red-emitting poly(p-phenylenevinylene) copolymers with narrow-band-gap units of 2,1,3-benzothiadiazole synthesized by a palladium-catalyzed Stille coupling reaction. J. Polym. Sci., Part A: Polym. Chem. 2005, 43 (11), 2325-2336.

(47) Zhang, S.; Hutchison, G. R.; Meyer, T. Y. Sequence Effects in Conjugated Donor-Acceptor Trimers and Polymers. Macromol. Rapid Commun. 2016, 37 (11), 882-887.

(48) Zhou, C.; Liang, Y.; Liu, F.; Sun, C.; Huang, X.; Xie, Z.; Huang, F.; Roncali, J.; Russell, T. P.; Cao, Y. Chain Length Dependence of the Photovoltaic Properties of Monodisperse Donor-Acceptor Oligomers as Model Compounds of Polydisperse Low Band Gap Polymers. Adv. Funct. Mater. 2014, 24 (47), 7538-7547.

(49) Li, W.; Albrecht, S.; Yang, L.; Roland, S.; Tumbleston, J. R.; McAfee, T.; Yan, L.; Kelly, M. A.; Ade, H.; Neher, D.; You, W. Mobility-Controlled Performance of Thick Solar Cells Based on Fluorinated Copolymers. J. Am. Chem. Soc. 2014, 136 (44), 1556615576 .

(50) Bartelt, J. A.; Lam, D.; Burke, T. M.; Sweetnam, S. M.; McGehee, M. D. Charge-Carrier Mobility Requirements for Bulk Heterojunction Solar Cells with High Fill Factor and External Quantum Efficiency > 90\%. Adv. Energy Mater. 2015, 5 (15), 1500577.

(51) Proctor, C. M.; Love, J. A.; Nguyen, T.-Q. Mobility Guidelines for High Fill Factor Solution-Processed Small Molecule Solar Cells. Adv. Mater. 2014, 26 (34), 5957-5961.

(52) Bartesaghi, D.; Perez, I. d. C.; Kniepert, J.; Roland, S.; Turbiez, M.; Neher, D.; Koster, L. J. A. Competition between recombination and extraction of free charges determines the fill factor of organic solar cells. Nat. Commun. 2015, 6, 7083.

(53) Zhan, C.-G.; Nichols, J. A.; Dixon, D. A. Ionization Potential, Electron Affinity, Electronegativity, Hardness, and Electron Excitation Energy: Molecular Properties from Density Functional Theory Orbital Energies. J. Phys. Chem. A 2003, 107 (20), 4184-4195.

(54) Rienstra-Kiracofe, J. C.; Tschumper, G. S.; Schaefer, H. F.; Nandi, S.; Ellison, G. B. Atomic and Molecular Electron Affinities: Photoelectron Experiments and Theoretical Computations. Chem. Rev. 2002, 102 (1), 231-282.

(55) Perdew, J. P.; Levy, M. Comment on "Significance of the highest occupied Kohn-Sham eigenvalue. Phys. Rev. B: Condens. Matter Mater. Phys. 1997, 56 (24), 16021.

(56) Levy, M. Excitation energies from density-functional orbital energies. Phys. Rev. A: At., Mol., Opt. Phys. 1995, 52 (6), R4313.

(57) Hutchison, G. R.; Ratner, M. A.; Marks, T. J. Accurate Prediction of Band Gaps in Neutral Heterocyclic Conjugated Polymers. J. Phys. Chem. A 2002, 106 (44), 10596-10605.

(58) Winget, P.; Weber, E. J.; Cramer, C. J.; Truhlar, D. G. Computational electrochemistry: aqueous one-electron oxidation potentials for substituted anilines. Phys. Chem. Chem. Phys. 2000, 2 (6), 1231-1239.

(59) Jaque, P.; Marenich, A. V.; Cramer, C. J.; Truhlar, D. G. Computational Electrochemistry: The Aqueous Ru3+|Ru2+ Reduction Potential. J. Phys. Chem. C 2007, 111 (15), 5783-5799.

(60) Zhou, H.; Yang, L.; You, W. Rational Design of High Performance Conjugated Polymers for Organic Solar Cells. Macromolecules 2012, 45 (2), 607-632.

(61) Sun, Y.; Welch, G. C.; Leong, W. L.; Takacs, C. J.; Bazan, G. C.; Heeger, A. J. Solution-processed small-molecule solar cells with $6.7 \%$ efficiency. Nat. Mater. 2011, 11 (1), 44-48.

(62) Zhang, Q.; Kan, B.; Liu, F.; Long, G.; Wan, X.; Chen, X.; Zuo, Y.; Ni, W.; Zhang, H.; Li, M.; Hu, Z.; Huang, F.; Cao, Y.; Liang, Z.; Zhang, M.; Russell, T. P.; Chen, Y. Small-molecule solar cells with efficiency over 9\%. Nat. Photonics 2014, 9, 35.

(63) Stuart, A. C.; Tumbleston, J. R.; Zhou, H.; Li, W.; Liu, S.; Ade, H.; You, W. Fluorine Substituents Reduce Charge Recombination and Drive Structure and Morphology Development in Polymer Solar Cells. J. Am. Chem. Soc. 2013, 135 (5), 1806-1815.

(64) Carsten, B.; Szarko, J. M.; Lu, L.; Son, H. J.; He, F.; Botros, Y. Y.; Chen, L. X.; Yu, L. Mediating Solar Cell Performance by Controlling the Internal Dipole Change in Organic Photovoltaic Polymers. Macromolecules 2012, 45 (16), 6390-6395.

(65) Carsten, B.; Szarko, J. M.; Son, H. J.; Wang, W.; Lu, L.; He, F.; Rolczynski, B. S.; Lou, S. J.; Chen, L. X.; Yu, L. Examining the Effect of the Dipole Moment on Charge Separation in Donor-Acceptor Polymers for Organic Photovoltaic Applications. J. Am. Chem. Soc. 2011, 133 (50), 20468-20475.

(66) Zhou, C.; Zhang, G.; Zhong, C.; Jia, X.; Luo, P.; Xu, R.; Gao, K.; Jiang, X.; Liu, F.; Russell, T. P.; Huang, F.; Cao, Y. Toward High Efficiency Polymer Solar Cells: Influence of Local Chemical Environment and Morphology. Adv. Energy Mater. 2016, 1601081.

(67) Zhang, Q.; Kelly, M. A.; Hunt, A.; Ade, H.; You, W. Comparative Photovoltaic Study of Physical Blending of Two Donor-Acceptor Polymers with the Chemical Blending of the Respective Moieties. Macromolecules 2016, 49 (7), 2533-2540.

(68) Jorgensen, M.; Krebs, F. C. Stepwise Unidirectional Synthesis of Oligo Phenylene Vinylenes with a Series of Monomers. Use in Plastic Solar Cells. J. Org. Chem. 2005, 70, 6004-6017.

(69) Lin, L.-Y.; Chen, Y.-H.; Huang, Z.-Y.; Lin, H.-W.; Chou, S.-H.; Lin, F.; Chen, C.-W.; Liu, Y.-H.; Wong, K.-T. A Low-Energy-Gap Organic Dye for High-Performance Small-Molecule Organic Solar Cells. J. Am. Chem. Soc. 2011, 133 (40), 15822-15825.

(70) Weininger, D. Smiles, a Chemical Language and InformationSystem 0.1. Introduction to Methodology and Encoding Rules. J. Chem. Inf. Model. 1988, 28 (1), 31-36.

(71) O'Boyle, N. M.; Banck, M.; James, C. A.; Morley, C.; Vandermeersch, T.; Hutchison, G. R. Open Babel: An open chemical toolbox. J. Cheminf. 2011, 3, 33.

(72) O’Boyle, N. M.; Morley, C.; Hutchison, G. R. Pybel: a Python wrapper for the OpenBabel cheminformatics toolkit. Chem. Cent. J. 2008, 2, 5 .

(73) Halgren, T. A. Merck molecular force field 0.1. Basis, form, scope, parameterization, and performance of MMFF94. J. Comput. Chem. 1996, 17 (5-6), 490-519.

(74) Halgren, T. A. Merck molecular force field 0.2. MMFF94 van der Waals and electrostatic parameters for intermolecular interactions. J. Comput. Chem. 1996, 17 (5-6), 520-552.

(75) Halgren, T. A. Merck molecular force field 0.3. Molecular geometries and vibrational frequencies for MMFF94. J. Comput. Chem. 1996, 17 (5-6), 553-586.

(76) Halgren, T. A. Merck molecular force field 0.5. Extension of MMFF94 using experimental data, additional computational data, and empirical rules. J. Comput. Chem. 1996, 17 (5-6), 616-641.

(77) Halgren, T. A.; Nachbar, R. B. Merck molecular force field 0.4. Conformational energies and geometries for MMFF94. J. Comput. Chem. 1996, 17 (5-6), 587-615.

(78) Frisch, M. J. T., G, W.; Schlegel, H. B.; Scuseria, G. E.; Robb, M. A.; Cheeseman, J. R.; Scalmani, G.; Barone, V.; Mennucci, B.; 
Petersson, G. A.; Nakatsuji, H.; Caricato, M.; Li, X.; Hratchian, H. P.; Izmaylov, A. F.; Bloino, J.; Zheng, G.; Sonnenberg, J. L.; Hada, M.; Ehara, M.; Toyota, K.; Fukuda, R.; Hasegawa, J.; Ishida, M.; Nakajima, T.; Honda, Y.; Kitao, O.; Nakai, H.; Vreven, T.; Montgomery, Jr., J. A.; Peralta, J. E.; Ogliaro, F.; Bearpark, M.; Heyd, J. J.; Brothers, E.; Kudin, K. N.; Staroverov, V. N.; Kobayashi, R.; Normand, J.; Raghavachari, K.; Rendell, A.; Burant, J. C.; Iyengar, S. S.; Tomasi, J.; Cossi, M.; Rega, N.; Millam, N. J.; Klene, M.; Knox, J. E.; Cross, J. B.; Bakken, V.; Adamo, C.; Jaramillo, J.; Gomperts, R.; Stratmann, R. E.; Yazyev, O.; Austin, A. J.; Cammi, R.; Pomelli, C.; Ochterski, J. W.; Martin, R. L.; Morokuma, K.; Zakrzewski, V. G.; Voth, G. A.; Salvador, P.; Dannenberg, J. J.; Dapprich, S.; Daniels, A. D.; Farkas, Ö.; Foresman, J. B.; Ortiz, J. V.; Cioslowski, J.; Fox, D. J. Gaussian 09, Revision A.2, Gaussian, Inc.: Wallingford CT, 2009.

(79) Becke, A. Density-functional thermochemistry. III. The role of exact exchange. J. Chem. Phys. 1993, 98 (7), 5648-5652.

(80) Lee, C.; Yang, W.; Parr, R. Development of the Colle-Salvetti correlation-energy formula into a functional of the electron density. Phys. Rev. B: Condens. Matter Mater. Phys. 1988, 37 (2), 785-789.

(81) Tomasi, J.; Mennucci, B.; Cammi, R. Quantum mechanical continuum solvation models. Chem. Rev. 2005, 105, 2999.

(82) Ridley, J.; Zerner, M. An Intermediate Neglect of Differential Overlap Technique for Spectroscopy: Pyrrole and the Azines. Theor. Chim. Acta 1973, 32, 111-134.

(83) Cossi, M.; Barone, V. Time-dependent density functional theory for molecules in liquid solutions. J. Chem. Phys. 2001, 115 (10), 47084717.

(84) Hanwell, M. D.; Curtis, D. E.; Lonie, D. C.; Vandermeersch, T.; Zurek, E.; Hutchison, G. R. Avogadro: an advanced semantic chemical editor, visualization, and analysis platform. J. Cheminf. 2012, 4, 17. 